\title{
openheart Subclinical sleep apnoea and plasma levels of endothelin-1 among young and healthy adults
}

\author{
Tobias Schoen, ${ }^{1,2,3}$ Stefanie Aeschbacher, ${ }^{2,3}$ Joerg D Leuppi, ${ }^{4}$ David Miedinger, ${ }^{4}$ \\ Ursina Werthmüller, ${ }^{5}$ Joel Estis, ${ }^{6}$ John Todd, ${ }^{6}$ Martin Risch, ${ }^{7,8}$ Lorenz Risch, ${ }^{7,9,10}$ \\ David Conen $2,3,11,12$
}

To cite: Schoen T, Aeschbacher S, Leuppi JD, et al. Subclinical sleep apnoea and plasma levels of endothelin-1 among young and healthy adults. Open Heart 2017;4:e000523. doi:10.1136/openhrt-2016000523

Received 21 August 2016 Revised 27 October 2016 Accepted 4 December 2016

CrossMark

For numbered affiliations see end of article.

Correspondence to Dr David Conen; david.conen@usb.ch

\section{ABSTRACT}

Objective: Obstructive sleep apnoea (OSA) is a risk factor for vascular disease and other adverse outcomes. These associations may be at least partly due to early endothelin-1 (ET-1)-mediated endothelial dysfunction (ED). Therefore, we assessed the relationships between subclinical sleep apnoea and plasma levels of ET-1.

Methods: We performed a population-based study among 1255 young and healthy adults aged 25-41 years. Cardiovascular disease, diabetes or a body mass index $>35 \mathrm{~kg} / \mathrm{m}^{2}$ were exclusion criteria. Plasma levels of ET-1 were measured using a highsensitivity, single-molecule counting technology. The relationships between subclinical sleep apnoea (OSA indices: respiratory event index (REI), oxygen desaturation index (ODI), mean night-time blood oxygen saturation $\left(\mathrm{SpO}_{2}\right)$ ) and $\mathrm{ET}-1$ levels were assessed by multivariable linear regression analysis.

Results: Median age of the cohort was 35 years. Median ET-1 levels were 2.9 (IQR 2.4-3.6) and $2.5 \mathrm{pg} / \mathrm{mL}$ (IQR 2.1-3.0) among patients with ( $\mathrm{n}=105$; $8 \%$ ) and without subclinical sleep apnoea (REI 5-14), respectively. After multivariable adjustment, subclinical sleep apnoea remained significantly associated with plasma levels of ET-1 ( $\beta=0.13(95 \% \mathrm{Cl} 0.06$ to 0.20$)$ $p=0.0002$ for a REI $5-14 ; \beta=0.10(95 \% \mathrm{Cl} 0.03$ to $0.16) \mathrm{p}=0.003$ for an $\mathrm{ODI} \geq 5$ ). Every $1 \%$ decrease in mean night-time $\mathrm{SpO}_{2}$ increased ET-1 levels by $0.1 \mathrm{pg} / \mathrm{mL}$, an association that remained significant after multivariable adjustment $(\beta=0.02(95 \% \mathrm{Cl} 0.003$ to 0.033$) \mathrm{p}=0.02$ ).

Conclusions: In this study of young and healthy adults, we found that participants with subclinical sleep apnoea had elevated plasma ET-1 levels, an association that was due to night-time hypoxaemia. Our results suggest that ED may already be an important consequence of subclinical sleep apnoea.

\section{INTRODUCTION}

Obstructive sleep apnoea (OSA) is a highly prevalent disorder, often underdiagnosed and significantly associated with adverse outcomes, including hypertension, ${ }^{1-5}$ stroke, ${ }^{6}$

\section{KEY QUESTIONS}

What is already known about this subject?

- Prior research has demonstrated a tight relationship of sleep apnoea with hypertension and other cardiovascular events among patients with clinical sleep apnoea syndrome.

What does this study add?

- This is the largest population-based study among young and healthy adults investigating the relationship of subclinical sleep apnoea and plasma endothelin-1 (ET-1) levels. This study demonstrates that apnoea-induced hypoxaemia is significantly related to increased ET-1 levels, suggesting that endothelial dysfunction may be an important consequence of obstructive sleep apnoea already at a subclinical stage.

How might this impact on clinical practice?

- This association is independent of other important cardiovascular risk factors (eg, smoking body mass index, blood pressure, renal function, high-sensitivity $\mathrm{C}$ reactive protein, glycated haemoglobin, low-density lipoprotein, highdensity lipoprotein) and supports the importance of even subclinical sleep apnoea in the development of cardiovascular disease.

coronary artery disease ${ }^{7} 8$ and sudden death. ${ }^{9} 10$

Although the precise pathophysiology linking OSA with vascular disease remains to be delineated, endothelial dysfunction (ED) may play a central role in this association. ${ }^{11} 12$ ED is characterised by reduced vasodilatation and enhanced vasoconstriction, as well as by increased prothrombotic and inflammatory activity ${ }^{13}$ In this context, endothelin-1 (ET-1) has been implicated as an important factor in the development of vascular dysfunction and cardiovascular disease, ${ }^{14-17}$ suggesting that ET-1 may be an easily measurable surrogate for endothelial function. ET-1 is released by endothelial cells and increases 
vascular tone by acting on underlying smooth muscle cells in a paracrine manner.

The resulting imbalance between vasodilator and vasoconstrictor endothelial mediators with overproduction of ET-1 increases vascular permeability and decreases antithrombotic activity, thereby promoting the occurrence of vascular disease. ${ }^{18} 19 \mathrm{ED}$ is therefore considered an early state of atherosclerosis and cardiovascular disease $^{20}$ and may constitute a potential link that relates OSA with adverse cardiovascular outcomes. Preliminary evidence from animal models of sleep apnoea and data from patients with OSA support this hypothesis, but data from large-scale population-based studies are currently unavailable. ${ }^{21}$ In addition, it remains unclear whether impaired vascular function is an early manifestation of OSA, or whether it may be a consequence of OSA-related comorbidities such as hypertension or obesity. Finally, quantification of endothelial function has been difficult and time-consuming, particularly in large-scale population-based studies. The emergence of new ET-1 assays facilitates its measurement and enables easier ET-1 quantification in large populations. ${ }^{22}$

To address some of these issues, we assessed the relationships between subclinical sleep apnoea (respiratory event index $($ REI $)=5-14$, oxygen desaturation index (ODI) $\geq 5$, mean night-time blood oxygen saturation $\left(\mathrm{SpO}_{2}\right)$, and per cent of sleeping time with $\left.\mathrm{SpO}_{2}<90 \%\right)$ and plasma levels of ET-1 in a large cohort of young and healthy adults.

\section{METHODS}

\section{Study participants}

The genetic and phenotypic determinants of blood pressure (BP) and other cardiovascular risk factors (GAPP) study is an ongoing prospective population-based cohort study in the Principality of Liechtenstein. Details about study design and methods have been described previously. ${ }^{23}$ Briefly, between May 2010 and December 2013, all inhabitants of the Principality of Liechtenstein aged 2541 years were invited to participate in GAPP. Exclusion criteria were a body mass index (BMI) $>35 \mathrm{~kg} / \mathrm{m}^{2}$, prevalent cardiovascular disease, known and treated sleep apnoea syndrome, renal failure, current intake of antidiabetic drugs or any other severe illnesses.

Of the 2170 included participants, 1415 (65\%) participants underwent night-time pulse oximetry with nasal flow measurement. To investigate effects of subclinical sleep apnoea, participants with a REI $\geq 15$ per hour $(n=25)$ were excluded to minimise confounding due to potentially undiagnosed OSA syndrome. Further, we excluded 135 participants due to missing or incomplete sleep study parameters $(\mathrm{n}=57)$, missing ambulatory BP recordings $(n=57)$ or other missing covariates $(n=21)$, such that 1255 participants remained for the current analyses. Written informed consent was obtained from each participant. The local ethics committee approved the study protocol.

\section{Night-time pulse oximetry}

Night-time pulse oximetry with nasal flow measurement was performed using the validated ApneaLink (ResMed, San Diego, California, USA) device ${ }^{24} 25$ to obtain information on night-time oxygen saturation, apnoeas and hypopnoeas. Sleep study analyses were based on automatic scoring analysis. The sleep study was performed at the patient's home. Individuals were instructed by a trained study nurse on how to put on the nasal cannula and the oximetry probe. An apnoea was defined as a reduction of nasal airflow of $\geq 80 \%$ compared with baseline for $\geq 10 \mathrm{~s}$. Hypopnoea was defined as a reduction of nasal airflow of $\geq 30 \%$ compared with baseline followed by a simultaneous decrease in oxygen saturation $\geq 4 \%$. The apnoea index was defined as the number of apnoeas per hour. The REI was defined as the number of apnoeas and hypopnoeas per hour of sleep according to the 2015 updated version of the American Academy of Sleep Medicine (AASM) criteria. $^{26-28}$ Subclinical sleep apnoea was defined to be present when the REI was 5 , but $<15$ per hour. The ODI was defined as the number of oxygen desaturations $\geq 4 \%$ per hour of sleep. ${ }^{29}$ An ODI of $\geq 5$ per hour was considered to be abnormal. In addition to REI and ODI, mean night-time $\mathrm{SpO}_{2}$ and the per cent of total sleep time with $\mathrm{SpO}_{2}<90 \%$ were calculated.

\section{BP assessment}

The 24 hours BP measurements were obtained using a validated device (BR-102 plus, Schiller AG, Switzerland). Trained study nurses handled the devices which were programmed to obtain BP measurements every $15 \mathrm{~min}$ during daytime and every $30 \mathrm{~min}$ during night-time. If participants had $<80 \%$ of valid measurements, the BP study was repeated whenever possible. BP measurements were only included in the analysis if $\geq 25$ daytime and $\geq 8$ nighttime measurements were available. Daytime and nighttime periods were individually defined through a 24-hour diary completed by each participant. Daytime hypertension was defined as mean systolic $\mathrm{BP} \geq 135 \mathrm{~mm} \mathrm{Hg}$ and/or mean diastolic $\mathrm{BP} \geq 85 \mathrm{~mm} \mathrm{Hg},{ }^{30}$ respectively. Night-time hypertension was defined as mean systolic $\mathrm{BP} \geq 120 \mathrm{~mm} \mathrm{Hg}$ and/or diastolic $\mathrm{BP} \geq 70 \mathrm{~mm} \mathrm{Hg}$, respectively. ${ }^{30}$ Individuals currently taking antihypertensive medication were considered to be hypertensive.

\section{Blood sampling}

Fasting venous blood samples were obtained from each participant and immediately centrifuged. Blood aliquots were immediately stored at $-80^{\circ} \mathrm{C}$. A research-use highsensitive, single-molecule counting assay (Erenna Immunoassay System, Singulex, Alameda, California, USA) was used to measure ET-1 from frozen EDTA plasma samples. ${ }^{22}$ The ET-1 assay's limits of blank and quantification were 0.07 and $0.33 \mathrm{pg} / \mathrm{mL}$, respectively. Interassay coefficients of variation were $7 \%$ at an ET-1 concentration of $1.2 \mathrm{pg} / \mathrm{mL}$ and $6 \%$ at an ET- 1 concentration of $1.8 \mathrm{pg} / \mathrm{mL}$. 
Plasma levels of glucose, creatinine, high-sensitive $\mathrm{C}$ reactive protein (hs-CRP), insulin, triglycerides (TG), high-density lipoprotein (HDL) and low-density lipoprotein (LDL) cholesterol were analysed on a Roche Cobas 6000 analyser (F. Hoffmann La Roche, Switzerland) using fresh blood samples. ${ }^{23}$ Glycated haemoglobin (HbA1c) was analysed using highperformance liquid chromatography (Bio-Rad D-10, Bio-Rad Laboratories AG, Switzerland). ${ }^{23}$ Pre-diabetes was defined as HbAlc between $5.7 \%$ and $6.4 \%$. For the estimation of the glomerular filtration rate (eGFR), we used the creatinine-based Chronic Kidney Disease Epidemiology Collaboration (CKD-EPI) formula. ${ }^{23}$

\section{Assessment of other study variables}

Questionnaires were used to obtain information about personal, medical, lifestyle and nutritional factors. Smoking status was self-assessed using three categories: current, past and never. BMI was calculated as body weight in kilogram divided by height in metres squared.

\section{Statistical analysis}

Distributions of continuous variables were evaluated using skewness, kurtosis and inspection of the histogram. Continuous variables were presented as medians (IQRs) and compared with the Wilcoxon rank sum test. Categorical variables were compared using $\chi^{2}$ tests. Owing to its distribution, ET-1 was used as a logtransformed variable in all analyses. Multivariable linear regression analyses were constructed using ET-1 as the outcome variable. Separate models were used to evaluate different sleep apnoea parameters, including REI, ODI, mean night-time $\mathrm{SpO}_{2}$ and per cent of sleeping time with a $\mathrm{SpO}_{2}<90 \%$. Age, sex and BMI adjusted models were further adjusted for a predefined set of covariates, including smoking status, HDL cholesterol, LDL cholesterol, TG, eGFR, HbA1c, mean systolic and diastolic ambulatory BP and hs-CRP.

Subgroup analyses were performed for age, sex, BMI, eGFR, hs-CRP, pre-diabetes, TG, smoking status, and daytime and/or night-time hypertension. Differences across subgroups were assessed by including multiplicative interaction terms in the non-stratified models. All analyses were performed using SAS V.9.4 (SAS Institute,

Table 1 Baseline characteristics according to subclinical sleep apnoea

\begin{tabular}{|c|c|c|c|}
\hline $\begin{array}{l}\text { Characteristic } \\
\mathrm{n}=1255\end{array}$ & $\begin{array}{l}\text { REI<5 } \\
n=1150 \text { (92\%) }\end{array}$ & $\begin{array}{l}\text { REI 5-14 } \\
n=105(8 \%)\end{array}$ & p Value* \\
\hline Age & $35(30-39)$ & $37(33-39)$ & 0.02 \\
\hline Males (\%) & 505 (44\%) & $85(81 \%)$ & $<0.0001$ \\
\hline Body mass index $\left(\mathrm{kg} / \mathrm{m}^{2}\right)$ & $23.9(21.7-26.5)$ & $27.0(23.5-30.1)$ & $<0.0001$ \\
\hline Endothelin (pg/mL) & $2.5(2.1-3.0)$ & $2.9(2.4-3.6)$ & $<0.0001$ \\
\hline eGFR, CKD-EPI (mL/min/1.73 m²) & $113(105-119)$ & $110(101-118)$ & 0.02 \\
\hline Creatinine $(\mu \mathrm{mol} / \mathrm{L})$ & $67(57-76)$ & $74(67-83)$ & $<0.0001$ \\
\hline High-sensitive CRP (mg/L) & $0.9(0.5-1.9)$ & $1.4(0.6-3.2)$ & 0.007 \\
\hline HbA1c (\%) & $5.4(5.1-5.6)$ & $5.4(5.2-5.7)$ & 0.17 \\
\hline \multicolumn{4}{|l|}{ 24-hour blood pressure (mm Hg) } \\
\hline Systolic & $122(114-130)$ & $128(119-136)$ & $<0.0001$ \\
\hline Diastolic & $77(72-82)$ & $81(76-86)$ & $<0.0001$ \\
\hline \multicolumn{4}{|l|}{ Daytime blood pressure $(\mathrm{mm} \mathrm{Hg})$} \\
\hline Systolic & $126(118-133)$ & $133(123-142)$ & $<0.0001$ \\
\hline Diastolic & $80(75-86)$ & $85(80-89)$ & $<0.0001$ \\
\hline \multicolumn{4}{|l|}{ Night-time blood pressure $(\mathrm{mm} \mathrm{Hg})$} \\
\hline Systolic & $107(101-115)$ & $112(107-120)$ & $<0.0001$ \\
\hline Diastolic & $65(60-70)$ & $68(63-74)$ & $<0.0001$ \\
\hline \multicolumn{4}{|l|}{ Office blood pressure $(\mathrm{mm} \mathrm{Hg})$} \\
\hline Systolic & $120(111-127)$ & $128(120-133)$ & $<0.0001$ \\
\hline Diastolic & $78(73-84)$ & $84(78-86)$ & $<0.0001$ \\
\hline Low-density lipoprotein (mmol/L) & $2.8(2.3-3.5)$ & $3.2(2.6-3.9)$ & $<0.0001$ \\
\hline High-density lipoprotein ( $\mathrm{mmol} / \mathrm{L})$ & $1.5(1.3-1.8)$ & $1.3(1.1-1.5)$ & $<0.0001$ \\
\hline Triglycerides (mmol/L) & $0.8(0.6-1.1)$ & $1.1(0.8-1.6)$ & $<0.0001$ \\
\hline \multicolumn{4}{|l|}{ Smoking } \\
\hline Current & 244 (21\%) & 32 (30\%) & 0.01 \\
\hline Past & $262(23 \%)$ & $22(21 \%)$ & 0.09 \\
\hline Never & 644 (56\%) & $51(49 \%)$ & 0.03 \\
\hline
\end{tabular}

Values are median (IQRs) or counts (percentages).

*Based on Kruskal-Wallis tests for continuous variables and $\chi^{2}$ tests for categorical variables.

CKD-EPI, Chronic Kidney Disease Epidemiology Collaboration; CRP, C reactive protein; eGFR, estimated glomerular filtration rate; HbA1c, glycated haemoglobin; REI, respiratory event index. 
Cary, North Carolina, USA). A p value $<0.05$ was used to indicate statistical significance.

\section{RESULTS}

\section{Baseline characteristics}

Baseline characteristics stratified by the presence or absence of subclinical sleep apnoea are presented in table 1. Of 1255 participants, 590 (47\%) were male. Subclinical sleep apnoea was found among $105(8 \%)$ participants according to a REI score between 5 and 14, 85 (81\%) men and 20 (19\%) women $(p<0.0001)$. Median ET-1 levels were $2.9 \mathrm{pg} / \mathrm{mL}$ (IQR 2.4-3.6) and $2.5 \mathrm{pg} / \mathrm{mL}$ (IQR 2.1-3.0) among patients with and without subclinical sleep apnoea $(\mathrm{p}<0.0001)$, respectively. Patients with subclinical sleep apnoea were significantly older (37 (IQR 33-39) vs 35 years (IQR 30-39) $\mathrm{p}=0.02)$, and had a higher BMI (27 vs $24 \mathrm{~kg} / \mathrm{m}^{2}$, $\mathrm{p}<0.0001$ ) and higher hs-CRP levels (1.4 (IQR 0.6-3.2) vs $0.9 \mathrm{mg} / \mathrm{L}$ (IQR $0.5-1.9$ ) $\mathrm{p}=0.0007$ ). They also had higher 24-hour ambulatory systolic (128 (IQR 119-136) vs $122 \mathrm{~mm} \mathrm{Hg}$ (IQR 114-130) $\mathrm{p}<0.0001$ ) and diastolic (81 (IQR 76-86) vs $77 \mathrm{~mm} \mathrm{Hg}$ (IQR 72-82) p<0.0001) BP levels, a higher prevalence of current smokers $(30 \%$ vs $21 \%, \mathrm{p}=0.01$ ), and lower HDL (1.3 (IQR 1.1-1.5) vs $1.5 \mathrm{mmol} / \mathrm{l}$ (IQR $1.3-1.8$ ) $\mathrm{p}<0.0001$ ) and higher LDL levels (3.2 (IQR 2.6-3.9) vs $2.8 \mathrm{mmol} / \mathrm{L}$ (IQR 2.3-3.5) $\mathrm{p}<0.0001)$, as shown in table 1 .

\section{Results of sleep study}

The results of the sleep study according to subclinical sleep apnoea are presented in table 2. All sleep apnoea indices were significantly different between both groups.

Table 2 Results of sleep study according to subclinical sleep apnoea*

\begin{tabular}{lccc}
\hline Characteristic & $\mathbf{R E I < 5}$ & $\mathbf{R E I} \mathbf{5 - 1 4}$ & \\
$\mathbf{n = 1 2 5 5}$ & $\mathbf{n = 1 1 5 0}(\mathbf{9 2 \% )}$ & $\mathbf{n = 1 0 5}(\mathbf{8 \%})$ & $\mathbf{p}$ Value† \\
\hline REI & $1(0-2)$ & $8(6-10)$ & $<0.0001$ \\
Oxygen desaturation index & $1(0-2)$ & $8(6-11)$ & $<0.0001$ \\
Oxygen desaturation index $\geq 5(\%)$ & $36(2 \%)$ & $88(71 \%)$ & $<0.0001$ \\
Mean night-time $\mathrm{SpO}_{2}(\%)$ & $95(94-96)$ & $93(92-95)$ & $<0.0001$ \\
Per cent of time with $\mathrm{SpO}_{2}<90 \%(\%)$ & $0.2(0-1.2)$ & $2.8(0.6-10.5)$ & $<0.0001$ \\
Apnoeas per hour & $0(0-1)$ & $2(1-4)$ & $<0.0001$ \\
Hypopnoeas per hour & $0(0-1)$ & $5(3-6)$ & 0.8 \\
Sleep duration (hours) & $7.3(6.5-8.0)$ & $7.3(6.3-8.0)$ & 0.13 \\
Mean heart rate (bpm) & $62(57-68)$ & $62(58-71)$ & 0.01 \\
Mean breathing rate (breaths/min) & $13(10-15)$ & $12(9-14)$ &
\end{tabular}

Values are median (IQRs), counts or percentages.

*Subclinical sleep apnoea was defined as REI $\geq 5$, but $<15$.

†Based on Kruskal-Wallis tests for continuous variables.

$\mathrm{REI}$, respiratory event index; $\mathrm{SpO}_{2}$, blood oxygen saturation.

Table 3 Sleep apnoea indices and plasma levels of endothelin-1

\begin{tabular}{|c|c|c|}
\hline $\mathrm{n}=1255$ & B (95\% Cl) & p Value \\
\hline & Respiratory event index 5-14 & \\
\hline Crude model & $0.17(0.10$ to 0.24$)$ & $<0.0001$ \\
\hline Age, sex and BMI adjusted model & $0.14(0.07$ to 0.21$)$ & $<0.0001$ \\
\hline \multirow[t]{2}{*}{ Multivariable model ${ }^{*}$} & $0.13(0.06$ to 0.20$)$ & 0.0002 \\
\hline & Oxygen-desaturation index $\geq 5$ & \\
\hline Crude model & $0.14(0.08$ to 0.20$)$ & $<0.0001$ \\
\hline Age, sex and BMI adjusted model & $0.11(0.04$ to 0.17$)$ & 0.0012 \\
\hline \multirow[t]{2}{*}{ Multivariable model ${ }^{*}$} & $0.10(0.03$ to 0.16$)$ & 0.003 \\
\hline & Mean night-time $\mathrm{SpO}_{2}(\%)$ & \\
\hline Crude model & $-0.034(-0.046$ to -0.021$)$ & $<0.0001$ \\
\hline Age, sex and BMI adjusted model & $-0.022(-0.036$ to -0.007$)$ & 0.003 \\
\hline \multirow[t]{2}{*}{ Multivariable model ${ }^{*}$} & $-0.018(-0.033$ to -0.003$)$ & 0.02 \\
\hline & Per cent of time with $\mathrm{SpO}_{2}<90 \%$ & \\
\hline Crude model & 0.021 (0.011 to 0.032$)$ & $<0.0001$ \\
\hline Age, sex and BMI adjusted model & $0.015(0.004$ to 0.025$)$ & 0.008 \\
\hline Multivariable model ${ }^{*}$ & $0.012(0.002$ to 0.023$)$ & 0.02 \\
\hline
\end{tabular}


Patients with subclinical sleep apnoea had a lower breathing rate, whereas sleep duration and mean heart rate were not different.

\section{Subclinical sleep apnoea and plasma ET-1 levels}

Linear regression models on the relationship between OSA indices and ET-1 levels are shown in table 3. In unadjusted models, subclinical sleep apnoea was significantly associated with log-transformed ET-1 $\quad(\beta=0.17$ (95\% CI 0.10 to 0.24$) \quad \mathrm{p}<0.0001$ for a REI 5-14). Multivariable adjustment slightly attenuated this relationship, but subclinical sleep apnoea remained strongly associated with ET-1 levels ( $\beta=0.13$ (95\% CI 0.06 to 0.20 ) $\mathrm{p}=0.0002$ for a REI 5-14). A similar robust association was found between ET-1 levels and an elevated ODI, present in 124 participants (multivariable-adjusted $\beta=0.10 \quad(95 \%$ CI 0.03 to 0.16$) \quad p=0.003)$. Every $1 \%$ decrease in mean night-time $\mathrm{SpO}_{2}$ resulted in an increase in the plasma concentration of ET-1 of $0.1 \mathrm{pg} /$ $\mathrm{mL}$, as shown in figure 1 . This association remained significant after multivariable adjustment $(\beta=0.02(95 \%$ CI 0.003 to 0.033 ) $\mathrm{p}=0.02$ ) (table 3 ). In addition, the per cent of sleeping time with $\mathrm{SpO}_{2}<90 \%$ was also associated with plasma levels of ET-1 (multivariable-adjusted $\beta=0.012$ (95\% CI 0.002 to 0.023 ) $p=0.02$ ). Figure 2 summarises the effect sizes of the different sleep apnoea indices on log-transformed plasma levels of ET-1.

\section{Subgroup analyses}

Subgroup analyses are presented in table 4 . We found a borderline significant sex by REI interaction ( $p$ value 0.049), suggesting that the association between subclinical sleep apnoea and ET-1 may be somewhat stronger among women ( $\beta=0.27$ (95\% CI 0.12 to 0.43 ) $\mathrm{p}=0.0005$ for a REI 5-14). No evidence for effect modification was found for the other parameters investigated, including age, BMI, pre-diabetes, smoking status, hypertension, eGFR, hs-CRP and TG.

\section{DISCUSSION}

To the best of our knowledge, this is the first large population-based study investigating the relationship between subclinical sleep apnoea and plasma levels of ET-1 among young and healthy adults. In our analysis, we found a strong and independent relationship between several OSA indices and plasma levels of ET-1 that was mainly mediated by hypoxaemia subsequent to apnoeas and hypopnoeas. All parameters related to intermittent or continuous hypoxaemia were significantly associated with ET-1 levels, including mean nighttime $\mathrm{SpO}_{2}$, per cent of sleeping time with $\mathrm{SpO}_{2}<90 \%$, ODI $\geq 5$ and REI 5-14. According to these findings, our data suggest that ED might already be present in subclinical sleep apnoea and that it may be directly caused by hypoxaemia. It is important to re-emphasize that confounding effects of undiagnosed OSA were minimised by excluding all participants with REI $\geq 15$.

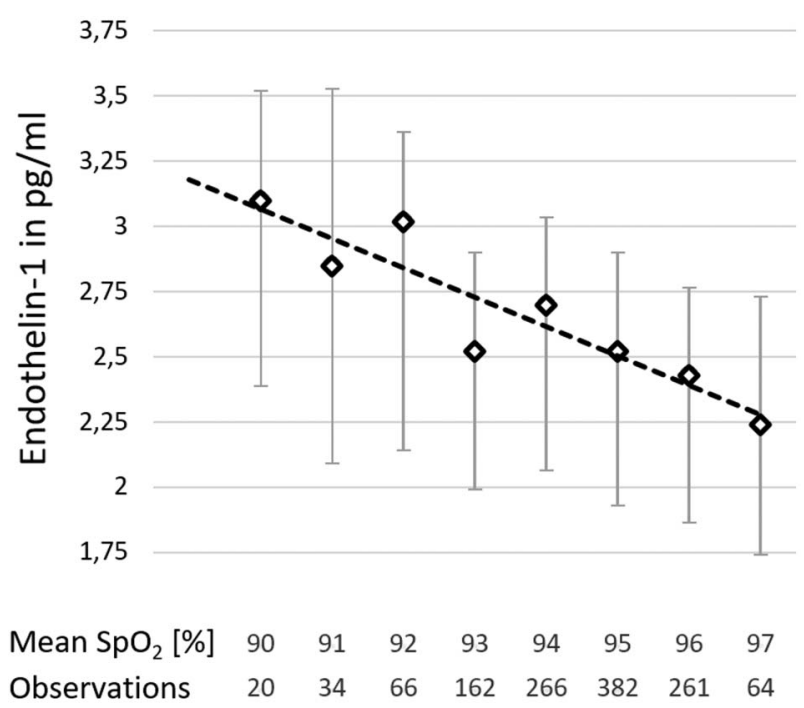

Figure 1 Median levels of plasma ET-1 according to mean night-time $\mathrm{SpO}_{2}$. Dashed line=regression line adjusted for age, sex, body mass index, high-sensitivity $C$ reactive protein, glomerular filtration rate, $\mathrm{HbA1c}$, systolic and diastolic ambulatory blood pressure, low-density lipoprotein, high-density lipoprotein, triglycerides and smoking status. ET-1, endothelin-1; HbA1c, glycated haemoglobin; Mean $\mathrm{SpO}_{2}$, mean night-time blood oxygen saturation.

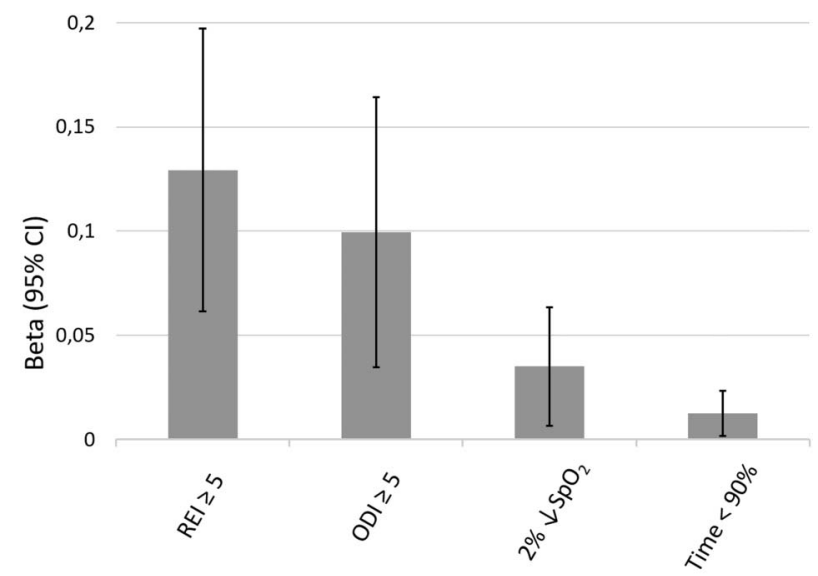

Figure 2 Sleep apnoea indices and plasma levels of endothelin-1. Multivariable linear regression models. Endothelin-1 was log-transformed. Adjustment for age, sex, body mass index, high-sensitivity $\mathrm{C}$ reactive protein, glomerular filtration rate, $\mathrm{HbA} 1 \mathrm{c}$, systolic and diastolic ambulatory blood pressure, low-density lipoprotein, high-density lipoprotein, triglycerides and smoking status. $\mathrm{SpO}_{2}$, mean night-time blood oxygen saturation. The $2 \% \downarrow$ $\mathrm{SpO}_{2}$ defined as the reduction of the mean night-time $\mathrm{SpO}_{2}$ by $2 \%$, for example, from $97 \%$ to $95 \%$. $\beta$, $\beta$ coefficient; $\mathrm{HbA1c}$, glycated haemoglobin; ODI, oxygen desaturation index; REI, respiratory event index; Time $<90 \%$, per cent of sleeping time with $\mathrm{SpO}_{2}<90 \%$.

If we assume that ET-1 is a direct marker of ED, ${ }^{17} 3132$ then taking into account competing risk factors for ED such as hypertension, diabetes and obesity is of utmost 
Table 4 Subclinical sleep apnoea and plasma levels of ET-1, stratified by selected baseline characteristics

\begin{tabular}{|c|c|c|c|}
\hline$n=1255$ & B (95\% Cl) & p Value & p Value for interaction \\
\hline \multicolumn{4}{|l|}{ Age } \\
\hline$<35$ years $(n=599)$ & & & 0.26 \\
\hline Multivariable model $^{*}$ & 0.17 (0.05 to 0.28$)$ & 0.004 & \\
\hline$\geq 35$ years $(n=656)$ & & & \\
\hline Multivariable model* & 0.10 (0.01 to 0.18$)$ & 0.03 & \\
\hline \multicolumn{4}{|l|}{ Sex } \\
\hline Men $(n=590)$ & & & 0.049 \\
\hline Multivariable model ${ }^{*}$ & $0.10(0.03$ to 0.17$)$ & 0.008 & \\
\hline Women $(n=665)$ & & & \\
\hline Multivariable model* & $0.27(0.12$ to 0.43$)$ & 0.0005 & \\
\hline \multicolumn{4}{|l|}{ BMI } \\
\hline$\geq 25 \mathrm{~kg} / \mathrm{m}^{2}(\mathrm{n}=507)$ & & & 0.16 \\
\hline Multivariable model $^{*}$ & 0.15 (0.06 to 0.24$)$ & 0.001 & \\
\hline$<25 \mathrm{~kg} / \mathrm{m}^{2}(\mathrm{n}=748)$ & & & \\
\hline Multivariable model ${ }^{*}$ & $0.08(-0.03$ to 0.19$)$ & 0.17 & \\
\hline \multicolumn{4}{|l|}{ Pre-diabetes } \\
\hline Yes $(n=278)$ & & & 0.28 \\
\hline Multivariable model ${ }^{*}$ & $0.11(-0.01$ to 0.23$)$ & 0.06 & \\
\hline \multicolumn{4}{|l|}{ No $(n=977)$} \\
\hline Multivariable model* & $0.14(0.05$ to 0.22$)$ & 0.001 & \\
\hline Smoking status & & & 0.09 \\
\hline Current Smoking* $(n=276)$ & $0.17(0.03$ to 0.31$)$ & 0.015 & \\
\hline Past Smoking* $(n=284)$ & $0.02(-0.13$ to 0.16$)$ & 0.83 & \\
\hline Never Smoking ${ }^{*}(n=695)$ & $0.18(0.08$ to 0.28$)$ & 0.0003 & \\
\hline \multicolumn{4}{|l|}{ Hypertension } \\
\hline Yes $(n=433)$ & & & 0.22 \\
\hline Multivariable model ${ }^{\star}$ & 0.10 (0.01 to 0.19$)$ & 0.03 & \\
\hline No $(n=822)$ & & & \\
\hline Multivariable model ${ }^{*}$ & $0.16(0.06$ to 0.27$)$ & 0.002 & \\
\hline
\end{tabular}

ET-1 was log-transformed. Hypertension was defined as mean ambulatory daytime blood pressure $\geq 135 / 85 \mathrm{~mm} \mathrm{Hg}$. Pre-diabetes was defined as $\mathrm{HbA} 1 \mathrm{c} \geq 5.7 \%$.

${ }^{*}$ Adjustment for age, sex, BMI, high-sensitivity $\mathrm{C}$ reactive protein, glomerular filtration rate, mean systolic and diastolic ambulatory blood pressure, low-density lipoprotein, high-density lipoprotein, triglycerides, $\mathrm{HbA} 1 \mathrm{c}$ and smoking status as appropriate.

$\beta, \beta$ coefficient; BMI, body mass index; ET-1, endothelin-1; HbA1c, glycated haemoglobin.

importance, because of the multifactorial and complex genesis of vascular dysfunction. It is therefore important to emphasise that our results remained highly significant after comprehensive multivariable adjustment. It is also noteworthy that our results were obtained in a cohort of young and healthy adults with very low plasma ET-1 levels and a low burden of comorbidities. Our findings suggest that even subclinical forms of OSA may impair endothelial function. In this context, our findings are in accordance with prior basic experimental studies showing that intermittent hypoxaemia impairs endothelial function ${ }^{33-35}$ and increases the production of ET-1 in cultured human endothelial cells ${ }^{14}$ as well as in vivo among untreated patients with severe OSA. ${ }^{36}$ Kato $e t a l^{37}$ showed an impairment of resistance-vessel endotheliumdependent vasodilation among eight middle-aged patients with OSA compared with nine control patients underscoring the relationship between OSA and hypertension. Finally, the magnitude of the association between subclinical sleep apnoea and ET-1 should also be stressed. We previously showed that in this cohort, elevated ET-1 levels were strongly related to currently smoking cigarettes. ${ }^{38}$ The $\beta$ coefficients for subclinical sleep apnoea exceeded those for smoking, underscoring the potential importance of subclinical sleep apnoea in the pathogenesis of cardiovascular disease.

Sex-specific analyses suggested that the relationship between subclinical sleep apnoea and ET-1 levels seems to be stronger among women. While the $p$ value of interaction was of borderline significance, there are recent studies also reporting sex-specific differences in the relationship between OSA and plasma levels of cardiac troponin $\mathrm{T}^{39}$ This study showed a significant association between a diagnosis of OSA and plasma levels of troponin $\mathrm{T}$ among middle-aged women but not men. ${ }^{39}$ These findings may suggest that the effect of OSA may be particularly deleterious among women, but further studies are needed to confirm this hypothesis.

The major strengths of this study include its population-based design and the large number of wellcharacterised young and healthy participants undergoing night-time pulse oximetry with nasal airflow measurement. In this population, exposure to environmental confounders is relatively short and individuals with pre- 
existing cardiovascular comorbidities were excluded. There are also some potential limitations that should be taken into consideration for the interpretation of our results. First, the cross-sectional design does not allow us to draw causal inferences or to assess the directionality of the observed effects. However, it is very unlikely that increased ET-1 levels induce night-time hypoxaemia, such that the latter seems to be the driving force for elevated ET-1 levels. ${ }^{40}$ Second, the generalisability of our results to other populations is uncertain. Third, we did not use polysomnography as the gold standard diagnostic tool for sleep apnoea. However, it has been shown that combining pulse oximetry with nasal flow measurement has a high sensitivity and specificity for detecting patients with sleep apnoea. ${ }^{24} 25$ Finally, we did not directly measure endothelial function in our population. However, previous studies showed a good correlation between plasma ET-1 levels and endothelial function. ${ }^{18}$

In conclusion, this study of young and healthy adults provides strong evidence of an independent relationship between subclinical sleep apnoea and plasma levels of ET-1. Our results further suggest that the increased ET-1 levels might be directly related to apnoea-induced hypoxaemia and that this phenomenon is already present in young and healthy individuals at a subclinical stage. These findings are independent of other important cardiovascular risk factors (eg, smoking, BMI, BP, renal function) and may, at least in part, explain the tight relationship of clinical sleep apnoea syndrome with hypertension and other adverse cardiovascular events.

\section{Author affiliations}

${ }^{1}$ Division of Cardiology, University Hospital Basel, Basel, Switzerland

${ }^{2}$ Cardiovascular Research Institute Basel, Basel, Switzerland

${ }^{3}$ Division of Internal Medicine, University Hospital Basel, Basel, Switzerland

${ }^{4}$ Medical University Clinic of Baselland and Medical Faculty of Basel, Liestal/ Basel, Switzerland

${ }^{5}$ Faculty of Medicine, University of Basel, Basel, Switzerland

${ }^{6}$ Singulex, Inc, Alameda, California, USA

${ }^{7}$ Labormedizinisches Zentrum Dr. Risch, Schaan, Liechtenstein

${ }^{8}$ Division of Laboratory Medicine, Kantonspital Graubünden, Chur, Switzerland

${ }^{9}$ Division of Clinical Biochemistry, Medical University Innsbruck, Austria

${ }^{10}$ Private University, Triesen, Liechtenstein

${ }^{11}$ Cardiology Division, St. Joseph's Healthcare, Hamilton, Ontario, Canada

${ }^{12}$ Population Health Research Institute, Vascular and Stroke Research

Institute, Hamilton, Ontario, Canada

Contributors TS and DC were involved in all parts of the conduct of this study: design of the study (TS, DC), acquisition of data (TS, DC), analysis and/or interpretation (TS, DC), drafting of the manuscript (TS), revising the manuscript (TS, DC). All other authors were involved in the conduct of this study and approved the revised version of the manuscript.

Funding The Liechtenstein Government, the Swiss Heart Foundation, the Swiss Society of Hypertension, the University of Basel, the University Hospital Basel, the Hanela Foundation, Schiller AG and Novartis supported the GAPP study. DC was supported by a grant of the Swiss National Science Foundation (PP00P3_133681 and PP00P3_159322). Endothelin-1 was measured free of charge by Singulex, Alameda, CA 94502, USA. The ApneaLink devices were provided by ResMed Schweiz AG (Basel, Switzerland)

Competing interests JT and JE are employees of Singulex and hold stock options in Singulex. They are also co-inventors on patents filed in regard to assay methods for measuring endothelin-1 levels.
Patient consent Obtained.

Ethics approval The local ethics committee approved the study protocol.

Provenance and peer review Not commissioned; externally peer reviewed.

Data sharing statement No additional data are available.

Open Access This is an Open Access article distributed in accordance with the Creative Commons Attribution Non Commercial (CC BY-NC 4.0) license, which permits others to distribute, remix, adapt, build upon this work noncommercially, and license their derivative works on different terms, provided the original work is properly cited and the use is non-commercial. See: http:// creativecommons.org/licenses/by-nc/4.0/

\section{REFERENCES}

1. Young T, Peppard P, Palta M, et al. Population-based study of sleep-disordered breathing as a risk factor for hypertension. Arch Intern Med 1997;157:1746-52.

2. Peppard PE, Young T, Palta M, et al. Prospective study of the association between sleep-disordered breathing and hypertension. N Engl J Med 2000;342:1378-84.

3. Nieto FJ, Young TB, Lind BK, et al. Association of sleep-disordered breathing, sleep apnea, and hypertension in a large community-based study. Sleep Heart Health Study. JAMA 2000;283:1829-36.

4. Bixler EO, Vgontzas AN, Lin HM, et al. Association of hypertension and sleep-disordered breathing. Arch Intern Med 2000;160:2289-95.

5. Lavie P, Herer P, Hoffstein V. Obstructive sleep apnoea syndrome as a risk factor for hypertension: population study. BMJ 2000;320:479-82

6. Arzt M, Young T, Finn L, et al. Association of sleep-disordered breathing and the occurrence of stroke. Am J Respir Crit Care Med 2005;172:1447-51.

7. Xie W, Zheng F, Song X. Obstructive sleep apnea and serious adverse outcomes in patients with cardiovascular or cerebrovascular disease: a PRISMA-Compliant Systematic Review and Meta-Analysis. Medicine (Baltimore) 2014;93:e336.

8. Shahar E, Whitney CW, Redline S, et al. Sleep-disordered breathing and cardiovascular disease: cross-sectional results of the Sleep Heart Health Study. Am J Respir Crit Care Med 2001;163:19-25.

9. Gami AS, Howard DE, Olson EJ, et al. Day-night pattern of sudden death in obstructive sleep apnea. N Engl J Med 2005;352:1206-14.

10. Gami AS, Olson EJ, Shen WK, et al. Obstructive sleep apnea and the risk of sudden cardiac death: a longitudinal study of 10,701 adults. J Am Coll Cardiol 2013;62:610-16.

11. Kohler M, Craig S, Nicoll D, et al. Endothelial function and arterial stiffness in minimally symptomatic obstructive sleep apnea. Am J Respir Crit Care Med 2008;178:984-8.

12. Kohler M, Craig S, Pepperell JCT, et al. CPAP improves endothelial function in patients with minimally symptomatic OSA: results from a subset study of the MOSAIC trial. Chest 2013;144:896-902.

13. Lurie A. Endothelial dysfunction in adults with obstructive sleep apnea. Adv Cardiol 2011;46:139-70.

14. Kourembanas S, Marsden PA, McQuillan LP, et al. Hypoxia induces endothelin gene expression and secretion in cultured human endothelium. J Clin Invest 1991;88:1054-7.

15. Amiri F, Virdis A, Neves MF, et al. Endothelium-restricted overexpression of human endothelin-1 causes vascular remodeling and endothelial dysfunction. Circulation 2004;110:2233-40.

16. Böhm F, Pernow J. The importance of endothelin-1 for vascular dysfunction in cardiovascular disease. Cardiovasc Res 2007;76:8-18.

17. Cooke AB, Toli E, Gomez YH, et al. From rest to stressed: endothelin-1 levels in young healthy smokers and non-smokers. Metab Clin Exp 2015;64:1103-11.

18. Masaki T, Sawamura T. Endothelin and endothelial dysfunction. Proc Jpn Acad Ser B Phys Biol Sci 2006;82:17-24.

19. Iglarz M, Clozel M. Mechanisms of ET-1-induced endothelial dysfunction. J Cardiovasc Pharmacol 2007;50:621-8.

20. Mudau M, Genis A, Lochner A, et al. Endothelial dysfunction: the early predictor of atherosclerosis. Cardiovasc J Afr 2012;23:222-31.

21. Azuma M, Chihara $Y$, Yoshimura $C$, et al. Association between endothelial function (assessed on reactive hyperemia peripheral arterial tonometry) and obstructive sleep apnea, visceral fat accumulation, and serum adiponectin. Circ J 2015;79:1381-9.

22. Todd J, Freese B, Lu A, et al. Ultrasensitive flow-based immunoassays using single-molecule counting. Clin Chem 2007;53:1990-5. 
23. Conen D, Schön T, Aeschbacher S, et al. Genetic and phenotypic determinants of blood pressure and other cardiovascular risk factors (GAPP). Swiss Med Wkly 2013;143:w13728.

24. Erman MK, Stewart D, Einhorn D, et al. Validation of the ApneaLink for the screening of sleep apnea: a novel and simple single-channel recording device. J Clin Sleep Med 2007;3:387-92.

25. Weinreich G, Armitstead J, Töpfer V, et al. Validation of ApneaLink as screening device for Cheyne-Stokes respiration. Sleep 2009;32:553-7.

26. Sleep-related breathing disorders in adults: recommendations for syndrome definition and measurement techniques in clinical research. The Report of an American Academy of Sleep Medicine Task Force. Sleep 1999;22:667-89.

27. Iber C, Ancoli-Israel S, Chesson AL Jr, et al., for the American Academy, of Sleep Medicine. The AASM manual for the scoring of sleep and associated events: rules, terminology and technical specifications. 1st edn. Westchester, IL: American Academy of Sleep Medicine, 2007.

28. Berry RB, Gamaldo CE, Harding SM, et al. AASM scoring manual version 2.2 updates: new chapters for scoring infant sleep staging and home sleep apnea testing. J Clin Sleep Med 2015;11:1253-4.

29. Dawson A, Loving RT, Gordon RM, et al. Type III home sleep testing versus pulse oximetry: is the respiratory disturbance index better than the oxygen desaturation index to predict the apnoea-hypopnoea index measured during laboratory polysomnography? BMJ Open 2015;5:e007956.

30. Mancia G, Fagard R, Narkiewicz K, et al. 2013 ESH/ESC guidelines for the management of arterial hypertension: the Task Force for the Management of Arterial Hypertension of the European Society of Hypertension (ESH) and of the European Society of Cardiology (ESC). Eur Heart J 2013;34:2159-219.
31. Perassolo MS, Almeida JC, Steemburgo T, et al. Endothelial dysfunction and serum fatty acid composition in patients with type 2 diabetes mellitus. Metab Clin Exp 2008;57:1167-72.

32. Hopfner RL, Gopalakrishnan V. Endothelin: emerging role in diabetic vascular complications. Diabetologia 1999;42:1383-94.

33. Carreras A, Zhang SX, Peris E, et al. Chronic sleep fragmentation induces endothelial dysfunction and structural vascular changes in mice. Sleep 2014;37:1817-24.

34. Foster GE, Brugniaux JV, Pialoux V, et al. Cardiovascular and cerebrovascular responses to acute hypoxia following exposure to intermittent hypoxia in healthy humans. $J$ Physiol (Lond) 2009;587:3287-99.

35. Foster GE, Poulin MJ, Hanly PJ. Intermittent hypoxia and vascular function: implications for obstructive sleep apnoea. Exp Physiol 2007:92:51-65.

36. Phillips BG, Narkiewicz K, Pesek CA, et al. Effects of obstructive sleep apnea on endothelin-1 and blood pressure. J Hypertens 1999;17:61-6.

37. Kato M, Roberts-Thomson P, Phillips BG, et al. Impairment of endothelium-dependent vasodilation of resistance vessels in patients with obstructive sleep apnea. Circulation 2000;102:2607-10.

38. Bossard M, Pumpol K, van der Lely S, et al. Plasma endothelin-1 and cardiovascular risk among young and healthy adults. Atherosclerosis 2015;239:186-91.

39. Roca GQ, Redline S, Claggett B, et al. Sex-Specific Association of Sleep Apnea Severity with Subclinical Myocardial Injury, Ventricular Hypertrophy, and Heart Failure Risk in a Community-Dwelling Cohort: the Atherosclerosis Risk in Communities-Sleep Heart Health Study. Circulation 2015:132:1329-37.

40. Dewan NA, Nieto FJ, Somers VK. Intermittent hypoxemia and OSA: implications for comorbidities. Chest 2015;147:266-74. 